ORIGINAL ARTICLE

\title{
Association of mid-pregnancy antioxidative vitamin and oxidative stress levels with infant growth during the first 3 years of life
}

\author{
Juhee Hong ${ }^{1,2}$, Hye Ah Lee ${ }^{2}$, Eun Ae Park ${ }^{3}$, Young-Ju Kim ${ }^{4}$. Hwayoung Lee ${ }^{5}$, \\ Bo-Hyun Park ${ }^{2}$, Eun-Hee Ha ${ }^{2}$, Kyoung Ae Kong ${ }^{6}$, Namsoo Chang ${ }^{7}$ and Hyesook Park ${ }^{2 *}$ \\ 'Office of Policy Development, Seoul Welfare Foundation, Seoul, South Korea; ${ }^{2}$ Department of Preventive \\ Medicine, School of Medicine, Medical Research Center, Ewha Womans University, Seoul, South Korea; \\ ${ }^{3}$ Department of Pediatrics, School of Medicine, Medical Research Center, Ewha Womans University, Seoul, \\ South Korea; ${ }^{4}$ Department of Obstetrics and Gynecology, School of Medicine, Medical Research Center, \\ Ewha Womans University, Seoul, South Korea; ${ }^{5}$ Department of Anatomy, School of Medicine, Medical Research \\ Center, Ewha Womans University, Seoul, South Korea; ${ }^{6}$ Ewha Clinical Trial Center, Ewha Womans University, School of \\ Medicine, Seoul, South Korea; ${ }^{7}$ Department of Nutritional Science and Food Management, College of Health Sciences, \\ Ewha Womans University, Seoul, South Korea
}

Abstract

Objective: Numerous studies have revealed the impacts of maternal nutritional status on subsequent birth outcome, but much less is known about the long-term impacts on infant growth after birth. We investigated the association between maternal micronutrient levels/oxidative stress status in pregnancy and infant growth during the first 3 years of life.

Design: Prospective cohort study.

Setting: The Ewha Birth \& Growth Cohort study was constructed for women who had been recruited between 24 and 28 weeks' gestation and their offspring at Ewha Womans University Hospital.

Subjects: Maternal serum vitamin and urinary oxidative stress levels were measured, and infant weight, height, and head circumference were measured repeatedly at birth and at 6, 12, 18, 24, and 36 months of age. Results: Maternal vitamins A and C were positively associated with infant head circumference and infant weight, respectively, during the first 3 years of life, even after controlling for potential confounding factors. But, maternal oxidative stress was not related to infant growth.

Conclusions: The effects of maternal vitamin levels on subsequent infant growth during the first 3 years of life necessitate interventions to supplement antioxidative vitamins during pregnancy.

Keywords: vitamins; oxidative stress; pregnancy; infant growth; birth outcome; cohort

Received: 3 December 20।3; Revised: 12 May 20।4; Accepted: 12 August 20।4; Published: 12 September 2014

$\mathrm{D}$ ifferent growth patterns among fetuses and infants of the same month of gestation age are known to predict later adulthood chronic disease (1). The causes of these growth differences can be multifactorial and include generic, prenatal, and postnatal factors $(2,3)$. In particular, undernutrition in utero during a certain period has detrimental effects on both infant growth and birth outcomes (4) because the supply of essential nutrients to the fetus and infant is totally dependent on maternal nutrition. Among all nutrients during pregnancy, antioxidant vitamins $\mathrm{A}, \mathrm{C}$, and $\mathrm{E}$ have been demonstrated to be essential micronutrients for the growth of fetuses and infants (5-7).

However, little is known about the potential associations, if any, between maternal antioxidant vitamins and oxidative stress and infant growth; previous findings have been inconclusive. Most studies have focused on birth outcomes such as birth weight or preterm delivery, assessing the impact of maternal vitamins using a crosssectional methodology rather than longitudinal observation. Some randomized controlled trials involving diet or nutrient supplementation for infants or pregnant women have observed growth patterns, but none have directly measured maternal biological levels from blood or urine. Moreover, none have considered the possible effects of various confounding factors on infant growth.

Therefore, we examined whether maternal serum antioxidant vitamins and urinary oxidative stress levels were associated with offspring growth during the first 3 years of life, with consideration of potential confounding factors. 


\section{Methods}

\section{Cohort construction}

This study was performed at Ewha Womans University Hospital, a representative hospital for women in Korea. The Ewha Birth \& Growth Cohort was constructed. From August 2001 to December 2004, a total of 800 apparently healthy women receiving antenatal care between 24 and 28 weeks of gestation at the hospital agreed to participate. Exclusion criteria were deliveries at other hospitals, pregnancy-induced hypertension and gestational diabetes, and no biological sample from the mothers. Among a total of 593 pregnant women, antioxidant vitamins and oxidative stress levels were measured and a baseline interview was conducted to obtain parental sociodemographic and anthropometrical characteristics on antenatal visits.

The cohort was constructed for 593 infants to whom enrolled pregnant women gave birth. Excluding twin births, preterm births, and congenital malformations, a total of 383 followed-up infants were analyzed.

This study was approved by the Institutional Review Board of Ewha Womans University Hospital, and informed consent was obtained from each woman at enrollment.

\section{Maternal vitamin and oxidative stress measurement}

The primary exposure variables were levels of maternal antioxidant vitamins and oxidative stress status in serum and urinary samples between 24 and 28 weeks of gestation. All fasting venous blood and urine samples obtained from the subjects were aliquoted and stored at $-70^{\circ} \mathrm{C}$ until analysis. Plasma vitamin A and E levels were measured by high-performance liquid chromatography (HPLC) using a reversed-phase column and an ultraviolet detector. For vitamin $\mathrm{C}$ analysis, plasma was mixed with $5 \%$ metaphosphoric acid, vortexed, and centrifuged for $10 \mathrm{~min}$ at $3,000 \times g$. The supernatant was filtered using a $0.45 \mu \mathrm{m}$ syringe filter, and $10 \mu \mathrm{L}$ samples were subjected to HPLC analysis. During the same period, the oxidative stress status was assessed by measuring the spontaneous urinary concentrations of $8-\mathrm{OHdG}$ (8-hydroxydeoxyguanine) and MDA (malondialdehyde). The amount of urinary $8-\mathrm{OHdG}$ was determined using a competitive in vitro ELISA (JICA, Fukuroi, Japan) for quantitative measurement of the oxidative DNA adducts. MDA was determined by HPLC for the adduct obtained with thiobarbituric acid (TBA).

For vitamins $\mathrm{A}$ and $\mathrm{E}$, the intra- and interassay coefficients of variation were 3 and $6 \%$, and those for vitamin $\mathrm{C}$ were 5 and $9 \%$, respectively. The urinary levels of $8-\mathrm{OHdG}$ and MDA are expressed as $\mu \mathrm{g} / \mathrm{g}$ creatinine and $\mu \mathrm{mol} / \mathrm{g}$ creatinine, respectively.

\section{Infants' anthropometric measurements}

After delivery, trained nurses in the delivery room routinely measured and recorded the birth weight, height, head circumference, and gestational age to compile the offspring data, and obtained the maternal age, weight, and height. Gestational age was assessed by the mother's estimated date of last menstrual period or by ultrasound measurement. Birth weight was measured to the nearest $50 \mathrm{~g}$, and the crown-heel length and head circumference were measured to the nearest $0.1 \mathrm{~cm}$. Twin births, maternal hypertension, gestational diabetes, and major congenital malformations were also recorded.

For measurements after birth, infants were followed up at $6,12,18,24$, and 36 months through outpatient clinic visits. When measurement at the clinic was not possible, a questionnaire asking for information on weight, height, head circumference, and general characteristics of the infant was mailed.

A Bland-Altman assessment (8) was used to assess the degree of agreement between these two measurement methods. The range of agreement was defined as the mean bias \pm 2 SD. The $95 \%$ limits of agreement between the clinical measurements and self-reported measurements ranged from -3.2 to 5.3 in height and from -1.2 to 1.5 in weight. The fact that the frequencies exceeding the difference between two measurements were 5.9\% for height and $4.7 \%$ for weight indicated that the selfreported measurements could be used as a substitute for direct measurements. Weight was measured to the nearest $0.01 \mathrm{~kg}$, and height and head circumference were measured to the nearest $0.1 \mathrm{~cm}$. Moreover, age- and sexspecific percentiles for weight, height, and head circumference based on the Korean National Growth Curves (9) were included using the LMS method (Lambda, mu, sigma) (10). The world health organization (WHO) Child Growth Standards were used for comparison with the international standards of weight and height (11).

\section{Confounding factors}

By mailed questionnaire, the following information on factors that may affect infant growth and maternal vitamin and oxidative stress levels was collected: first weaning month, breastfeeding, mother's employment status, secondhand smoke exposure, caregiver (mother or other individual), infant dietary supplementation, hospital admission history, parental education period, and household income.

\section{Statistical analysis}

Levels of maternal vitamins and oxidative stress were dichotomized into low/high groups at the 25 th or 75 th percentile as determined by the distribution of serum or urinary concentrations among the entire cohort. The rationale for using different percentiles is that for vitamin A as the 25th percentile, a deficiency effect was important; for vitamins $\mathrm{C}$ and $\mathrm{E}$ as the 75th percentile, a supplementing effect was important; and for $8-\mathrm{OHdG}$ and MDA as the 75 th percentile, an excess effect was important.

Between the two low/high groups, the mean infant weight, height, head circumference, weight percentile, height percentile, and head circumference percentile at 
birth and at $6,12,18,24$, and 36 months were assessed using the PROC Mixed procedure in the Statistical Analysis Systems statistical software package version 9.1 for Windows (SAS Institute, Cary, NC, USA).

The Student's $t$ test and chi-squared test were conducted to select confounding factors. Finally, we selected the five potential confounding variables that provided valid and precise results.

\section{Results}

\section{General characteristics of the study population}

A total of 383 infants whose mothers' vitamin and oxidative stress levels were measured were followed up at least once between birth and 36 months (follow-up rate of $64.5 \%$ ). Table 1 lists the number of infants followed at birth and at $6,12,18,24$, and 36 months as well as their mean weight, height, and head circumference. Figure 1 shows that the weight, height, and head circumference from birth to 36 months were all higher in male than in female infants. All measurements were within the normal ranges based on comparison with the Korean National Growth Curves (Fig. 1) and WHO Child Growth Standards $(9,11)$. The levels of maternal antioxidant vitamins and oxidative stress and the general characteristics of the mothers, fathers, and infants, are shown in Table 2.

A total of 383 infants were followed up, and 124 infants dropped out during follow-up. The differences among these infants were in the maternal vitamin A level $(p=0.01)$ and caregiver (mother or other individual) $(p<0.0001)$ (Table 3).

\section{Relationship between maternal vitamin and oxidative stress levels and infant growth}

Because gestational age and infant sex were thought to be the primary confounding variables for the association between maternal vitamin levels and infant growth, these two variables were adjusted first (Table 4). A high maternal concentration of vitamin $\mathrm{C}$ was significantly associated with increased infant weight $(p=0.02)$ and head circumference $(p=0.03)$ during the first 3 years of life.
Conversely, a high maternal MDA was associated with decreased infant weight $(p=0.01)$ and height $(p=0.01)$. Similarly, infants with a high maternal concentration of vitamin $\mathrm{E}$ showed a lower weight and height, but only the association with height was statistically significant $(p=0.02)$. Next, other potential confounders including gestational age, infant sex, breastfeeding, period of breastfeeding, household income, and dietary supplementation were adjusted in the final model. After adjustment for these variables, the group with low maternal vitamin A presented a lower head circumference percentile than the group with high maternal vitamin A $(p<0.01)$. Likewise, the vitamin $C$ group showed a similar pattern in head circumference percentiles, but there was no statistical significance $(p=0.34)$; they also weighed less than subjects in the high vitamin $\mathrm{C}$ group $(p=0.01)$ (Table 5). In the mixed model, there was a significant interaction between maternal vitamin $\mathrm{A}$ intake and age in terms of head circumference when adjusting for confounding variables (Fig. 2). This denotes that these indices increased to a greater extent in the high vitamin $\mathrm{A}$ and $\mathrm{C}$ groups than in the low group as individuals became older. In particular, the effect of age on increased weight was modified by maternal antioxidative vitamin levels in that a stronger effect was seen in the group with high vitamin $\mathrm{C}$ intake than in the group with low vitamin $\mathrm{C}$ intake. The anthropometric measurements of oxidative stress in the high oxidative stress group were lower than those in the low oxidative stress group, but the differences were not statistically significant.

\section{Discussion}

To the best of our knowledge, this is the first study to show an association between levels of antioxidant vitamins and oxidative stress in mothers and infant growth during the first 3 years of life. Our findings indicate that maternal vitamin $\mathrm{A}$ and $\mathrm{C}$ increase the head circumference and weight of infants for 3 years within a normal growth range even after considering other relevant factors associated with infant growth. Maternal oxidative stress does not have an effect on infant growth in the first 3 years of life.

Table 1. Anthropometric parameters of infants at birth and at $6,12,18,24$, and 36 months $^{\text {a }}$

\begin{tabular}{lcccccc}
\hline Parameter & At birth & 6 months & 12 months & 18 months & 24 months & 36 months \\
\hline Weight $(\mathrm{kg})$ & $3.3 \pm 0.4(383)$ & $8.3 \pm 1.0(250)$ & $10.0 \pm 1.2(259)$ & $11.4 \pm 1.4(196)$ & $12.6 \pm 1.3(17 I)$ & $15.2 \pm 1.8(124)$ \\
Height $(\mathrm{cm})$ & $49.4 \pm 2.1(383)$ & $68.9 \pm 3.1(173)$ & $76.8 \pm 3.2(221)$ & $82.6 \pm 3.7(155)$ & $87.8 \pm 3.5(142)$ & $98.3 \pm 4.6(124)$ \\
Head circumference $(\mathrm{cm})$ & $34.4 \pm 1.4(382)$ & $43.6 \pm 1.8(80)$ & $46.0 \pm 1.7(128)$ & $47.6 \pm 1.4(67)$ & $48.6 \pm 1.6(83)$ & $50.0 \pm 1.5(119)$ \\
Weight percentile & $45.0 \pm 24.6(382)$ & $62.5 \pm 28.8(250)$ & $58.9 \pm 28.0(259)$ & $57.9 \pm 28.0(196)$ & $57.8 \pm 26.7(17 I)$ & $67.4 \pm 26.2(124)$ \\
Height percentile & $51.2 \pm 22.9(383)$ & $58.8 \pm 28.7(173)$ & $57.6 \pm 28.8(221)$ & $57.4 \pm 27.8(155)$ & $60.5 \pm 27.7(142)$ & $75.2 \pm 25.9(124)$ \\
Head circumference percentile & $56.7 \pm 25.7(382)$ & $66.5 \pm 27.2(80)$ & $65.5 \pm 26.8(128)$ & $65.7 \pm 25.4(67)$ & $64.2 \pm 28.7(83)$ & $69.0 \pm 23.3(118)$ \\
\hline
\end{tabular}

Units: mean \pm standard deviation $(N)$.

${ }^{a}$ Numbers vary due to missing data. 

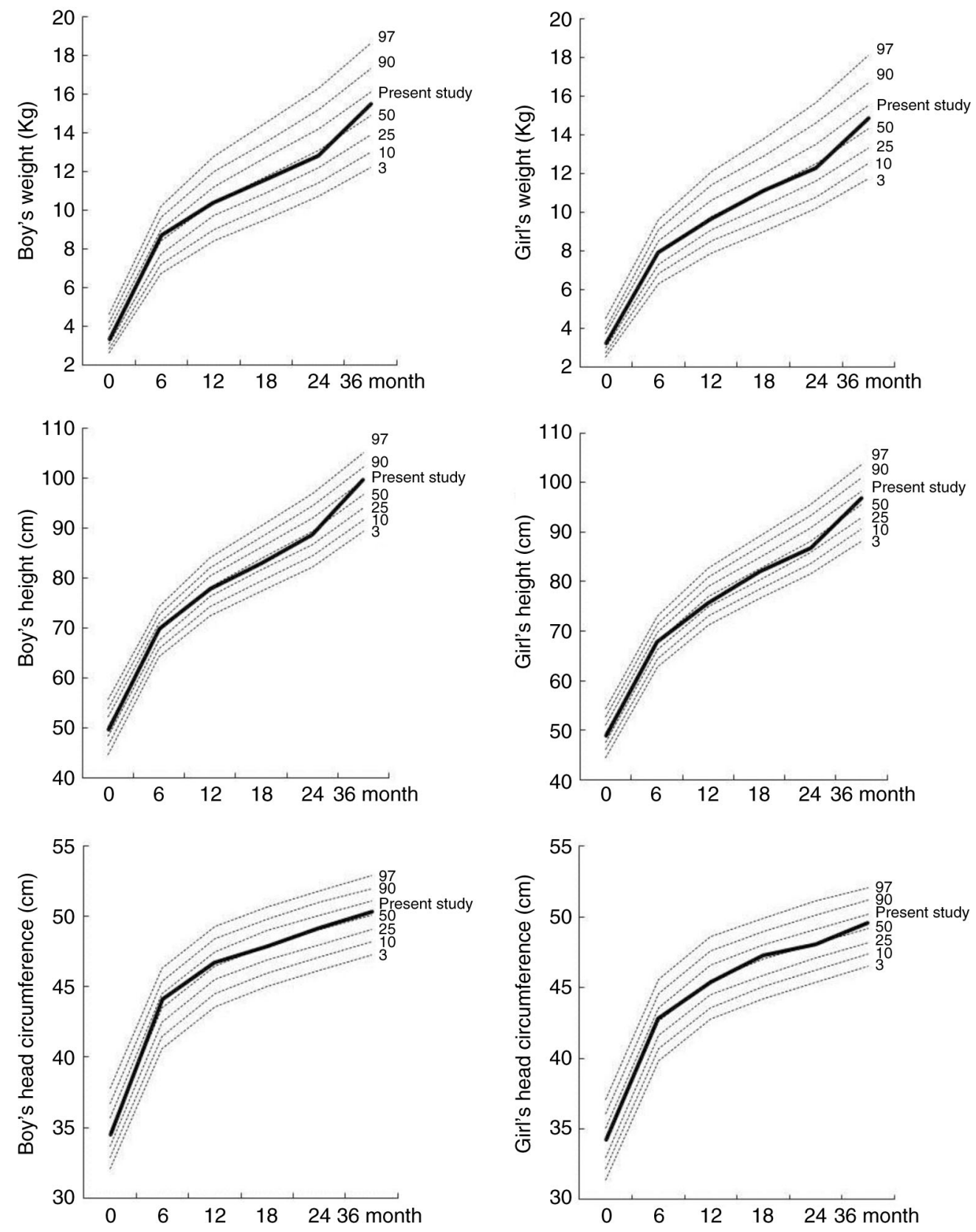

Fig. 1. Comparison of data with Korean National Growth Curve. Source: Korean Pediatric Society (9).

The black solid line represents the data of the present study.

Although there are various methods for measuring maternal nutrition levels, including measuring the supplementation effect of a specific nutrient, the most precise method is to measure a nutrient directly in maternal serum. A few studies have used maternal serum samples to examine the effects of specific maternal nutrients on infant growth, but the results have been inconsistent.

Most studies that have examined the effects of maternal nutrition on infant growth have focused only on birth outcome, not on continuous growth after birth. In particular, some studies observed only weight (12), and only a few studies used other anthropometric measurements such as infant height $(13,14)$, head circumference $(13,15)$, or the ponderal index (birth weight/height $\left.{ }^{3}\right)(16)$. Along with weight and height, head circumference is an important body measurement for motor and cognitive development. There have been reports on an association between neurological development indices and head circumference, but not weight or height $(17,18)$. Hence, we measured head circumference as well as weight and height and, in particular, included the standardized percentiles of weight, height, and head circumference that 
Table 2. General characteristics of the study population ${ }^{\mathrm{a}}$

\begin{tabular}{|c|c|c|}
\hline Characteristics & $N$ & Mean \pm SD or $N(\%)$ \\
\hline \multicolumn{3}{|l|}{ Mothers } \\
\hline Vitamin $A(\mu g / d L)$ & 366 & $100.02 \pm 34.54$ \\
\hline Vitamin $C(\mu \mathrm{g} / \mathrm{mL})$ & 353 & $7.49 \pm 2.46$ \\
\hline Vitamin $E(\mu g / d L)$ & 365 & $1654.96 \pm 463.84$ \\
\hline MDA ( $\mu$ mol/g creatinine) & 136 & $2.33 \pm 1.11$ \\
\hline 8-OHdG ( $\mu \mathrm{g} / \mathrm{g}$ creatinine) & 133 & $0.12 \pm 0.04$ \\
\hline Age at delivery (years) & 382 & $31.2 \pm 3.5$ \\
\hline Weight (kg) & 329 & $54.3 \pm 6.9$ \\
\hline Height $(\mathrm{cm})$ & 331 & $161.1 \pm 5.0$ \\
\hline \multicolumn{3}{|l|}{ Employment status } \\
\hline Employed & \multirow{2}{*}{315} & $113(35.9)$ \\
\hline Unemployed & & $202(64.1)$ \\
\hline \multicolumn{3}{|l|}{ Education period } \\
\hline$<12$ years & \multirow{3}{*}{253} & $63(24.9)$ \\
\hline $13-16$ years & & $156(6 \mid .7)$ \\
\hline$>17$ years & & $34(13.4)$ \\
\hline \multicolumn{3}{|l|}{ Fathers } \\
\hline Weight (kg) & 329 & $72.6 \pm 9.3$ \\
\hline Height $(\mathrm{cm})$ & 330 & $174.1 \pm 5.0$ \\
\hline \multicolumn{3}{|l|}{ Education period } \\
\hline$<12$ years & \multirow{3}{*}{257} & $36(14.0)$ \\
\hline $13-16$ years & & $172(66.9)$ \\
\hline$>17$ years & & $49(19.1)$ \\
\hline \multicolumn{3}{|c|}{ Household income (10,000 won) } \\
\hline$<100$ & \multirow{4}{*}{256} & $2(0.8)$ \\
\hline $100-199$ & & $60(23.4)$ \\
\hline $200-299$ & & $112(43.8)$ \\
\hline$>300$ & & $82(32.0)$ \\
\hline \multicolumn{3}{|l|}{ Infants } \\
\hline Gestational age (weeks) & 383 & $39.2 \pm 1.7$ \\
\hline \multicolumn{3}{|l|}{ Sex } \\
\hline Male & \multirow[b]{2}{*}{383} & $201(52.5)$ \\
\hline Female & & $181(47.3)$ \\
\hline Weaning period (months) & 262 & $5.4 \pm 1.2$ \\
\hline \multicolumn{3}{|l|}{ Breast feeding } \\
\hline Yes & \multirow{2}{*}{318} & $273(85.9)$ \\
\hline No & & $45(14.2)$ \\
\hline Period of breastfeeding ${ }^{b}$ & 188 & $6.0(3.0-13.0)$ \\
\hline \multicolumn{3}{|l|}{ Caregiver } \\
\hline Mother & \multirow{2}{*}{383} & $299(78.1)$ \\
\hline Other & & $84(21.9)$ \\
\hline \multicolumn{3}{|l|}{ Dietary supplementation } \\
\hline Yes & \multirow{2}{*}{296} & $134(45.3)$ \\
\hline No & & $162(54.7)$ \\
\hline \multicolumn{3}{|l|}{ Hospital admission history } \\
\hline Yes & \multirow[b]{2}{*}{312} & $85(27.2)$ \\
\hline No & & $227(72.8)$ \\
\hline \multicolumn{3}{|l|}{ Secondhand smoke exposure } \\
\hline No & & $225(70.3)$ \\
\hline In-house & 320 & $70(21.9)$ \\
\hline Out-house & & $25(7.8)$ \\
\hline
\end{tabular}

SD: standard deviation.

${ }^{a}$ Numbers vary due to missing data; ${ }^{b}$ median with interquartile range.
Table 3. Comparison of followed-up and non-followed-up population ${ }^{\mathrm{a}}$

\begin{tabular}{|c|c|c|c|}
\hline & Total & $\begin{array}{l}\text { Follow-up loss } \\
\qquad(n=124)\end{array}$ & $\begin{array}{l}\text { Followed up } \\
\qquad(n=383)\end{array}$ \\
\hline Characteristics & $N$ & \multicolumn{2}{|c|}{$N(\%)$ or Mean } \\
\hline \multicolumn{4}{|l|}{ Mothers } \\
\hline \multicolumn{4}{|c|}{ Vitamin A $(\mu \mathrm{g} / \mathrm{dL})^{*}$} \\
\hline Low & 135 & 44 (37.3) & 91 (24.9) \\
\hline High & 349 & $74(62.7)$ & $275(75.1)$ \\
\hline \multicolumn{4}{|l|}{ Vitamin $C(\mu \mathrm{g} / \mathrm{mL})$} \\
\hline Low & 340 & $75(69.4)$ & $265(75.1)$ \\
\hline High & 121 & $33(30.6)$ & $88(24.9)$ \\
\hline \multicolumn{4}{|l|}{ Vitamin $E(\mu g / d L)$} \\
\hline Low & 367 & $93(78.8)$ & $274(75.1)$ \\
\hline High & 116 & $25(21.2)$ & 9I (24.9) \\
\hline \multicolumn{4}{|l|}{ MDA $(\mu \mathrm{mol} / \mathrm{g}$} \\
\hline Low & 155 & $53(74.7)$ & $102(75.0)$ \\
\hline High & 52 & $18(25.4)$ & $34(25.0)$ \\
\hline \multicolumn{4}{|l|}{$\begin{array}{l}\text { 8-OHdG ( } \mu g / g \\
\text { creatinine) }\end{array}$} \\
\hline Low & 156 & $57(80.3)$ & $99(74.4)$ \\
\hline High & 48 & $14(19.7)$ & $34(25.6)$ \\
\hline $\begin{array}{l}\text { Age at delivery } \\
\text { (years) }\end{array}$ & 506 & 31.0 & 31.6 \\
\hline Weight $(\mathrm{kg})$ & 340 & 55.02 & 54.96 \\
\hline Height $(\mathrm{cm})$ & 342 & 161.79 & $|60.8|$ \\
\hline \multicolumn{4}{|l|}{ Infants } \\
\hline \multicolumn{4}{|l|}{ Sex } \\
\hline Male & 262 & 61 (49.6) & $20 \mathrm{I}(52.5)$ \\
\hline Female & 243 & $62(50.4)$ & $|8|(47.3)$ \\
\hline $\begin{array}{l}\text { Gestational age } \\
\text { (weeks) }\end{array}$ & 507 & 38.82 & 38.90 \\
\hline Birth weight $(\mathrm{kg})$ & 507 & 3.18 & 3.19 \\
\hline \multicolumn{4}{|l|}{ Breast feeding } \\
\hline Yes & 277 & $4(80.0)$ & $273(85.9)$ \\
\hline No & 46 & I (20.0) & $45(14.2)$ \\
\hline \multicolumn{4}{|l|}{ Caregiver** } \\
\hline Mother & 304 & $5(4.0)$ & $299(78.1)$ \\
\hline Other & 203 & $119(96.0)$ & $84(21.9)$ \\
\hline \multicolumn{4}{|l|}{$\begin{array}{l}\text { Dietary } \\
\text { supplementation }\end{array}$} \\
\hline Yes & 135 & I (20.0) & $134(45.3)$ \\
\hline No & 166 & $4(80.0)$ & $162(54.7)$ \\
\hline
\end{tabular}

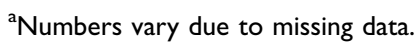

${ }^{*} p<0.05,{ }^{* *} p<0.01$.

were recommended for assessing anthropometric growth (19). No studies have used percentile parameters to evaluate the association between maternal nutritional status and infant growth.

It is not possible to compare the findings of this study with those of other studies because no other studies have 
Table 4. Association between levels of maternal antioxidant vitamins and oxidative stress and infant growth percentile adjusted for infant sex and gestational age

\begin{tabular}{|c|c|c|c|c|c|c|c|c|c|c|}
\hline \multirow[b]{2}{*}{ Infant growth } & \multicolumn{2}{|c|}{ Vitamin A } & \multicolumn{2}{|c|}{ Vitamin C } & \multicolumn{2}{|c|}{ Vitamin $E$} & \multicolumn{2}{|c|}{ MDA } & \multicolumn{2}{|c|}{ 8-OHdG } \\
\hline & Low & High & Low & High & Low & High & Low & High & Low & High \\
\hline \multicolumn{11}{|l|}{ Weight } \\
\hline At birth & 43.96 & 45.00 & 45.04 & 44.40 & 45.20 & 43.44 & 45.22 & 39.35 & 44.81 & 40.14 \\
\hline 6 months & 57.44 & 63.44 & 59.97 & 68.53 & 61.74 & 63.13 & 60.69 & 50.99 & 57.98 & 59.11 \\
\hline 12 months & 59.35 & 58.56 & 56.34 & 65.68 & 58.15 & 60.30 & 58.00 & 52.20 & 57.61 & 53.42 \\
\hline 18 months & 63.46 & 55.91 & 56.43 & 58.95 & 58.02 & 55.56 & 59.95 & 41.67 & 54.66 & 57.49 \\
\hline 24 months & 57.13 & 56.58 & 53.89 & 61.26 & 56.96 & 55.55 & 56.83 & 47.92 & 55.44 & 53.63 \\
\hline 36 months & 75.15 & 67.13 & 66.12 & 73.26 & 70.91 & 62.56 & 77.47 & 65.80 & 74.89 & 71.65 \\
\hline$p$ & \multicolumn{2}{|c|}{0.50} & \multicolumn{2}{|c|}{0.02} & \multicolumn{2}{|c|}{0.45} & \multicolumn{2}{|c|}{0.01} & \multicolumn{2}{|c|}{0.67} \\
\hline \multicolumn{11}{|l|}{ Height } \\
\hline At birth & 50.08 & 50.49 & 49.69 & 51.40 & 50.34 & 50.43 & 50.13 & 46.00 & 50.81 & 44.22 \\
\hline 6 months & 56.95 & 57.78 & 57.27 & 59.43 & 59.66 & 51.82 & 55.24 & 56.08 & 56.55 & 57.97 \\
\hline 12 months & 58.53 & 55.73 & 55.20 & 58.32 & 56.86 & 55.11 & 53.96 & 41.24 & 53.61 & 45.98 \\
\hline 18 months & 60.36 & 56.24 & 54.57 & 60.99 & 59.13 & 50.64 & 59.32 & 43.03 & 57.97 & 34.25 \\
\hline 24 months & 57.75 & 60.07 & 60.27 & 56.21 & 60.92 & 56.51 & 61.01 & 52.47 & 59.07 & 59.55 \\
\hline 36 months & 87.95 & 74.44 & 73.84 & 84.19 & 79.46 & 70.41 & 89.38 & 76.11 & 86.31 & 86.39 \\
\hline$p$ & \multicolumn{2}{|c|}{0.25} & \multicolumn{2}{|c|}{0.16} & \multicolumn{2}{|c|}{0.02} & \multicolumn{2}{|c|}{0.01} & \multicolumn{2}{|c|}{0.13} \\
\hline \multicolumn{11}{|c|}{ Head circumference } \\
\hline At birth & 55.87 & 55.94 & 56.56 & 56.05 & 56.29 & 54.93 & 54.72 & 51.33 & 54.49 & 52.26 \\
\hline 6 months & 52.67 & 69.99 & 65.18 & 72.49 & 66.43 & 70.02 & 72.11 & 55.57 & 65.99 & 71.58 \\
\hline 12 months & 62.90 & 68.08 & 63.92 & 75.89 & 65.40 & 73.33 & 67.95 & 49.60 & 67.63 & 57.05 \\
\hline 18 months & 69.46 & 66.14 & 65.31 & 69.97 & 67.21 & 64.87 & 60.90 & 65.61 & 64.22 & 69.67 \\
\hline 24 months & 57.36 & 67.03 & 63.69 & 73.83 & 67.37 & 62.79 & 66.63 & 61.97 & 64.99 & 68.24 \\
\hline 36 months & 68.88 & 70.10 & 70.11 & 72.62 & 69.05 & 71.94 & 70.16 & 69.38 & 69.28 & 72.72 \\
\hline$P$ & \multicolumn{2}{|c|}{0.12} & \multicolumn{2}{|c|}{0.03} & \multicolumn{2}{|c|}{0.71} & \multicolumn{2}{|c|}{0.12} & \multicolumn{2}{|c|}{0.89} \\
\hline
\end{tabular}

Adjusted for infant sex and gestational age.

examined this association over a relatively long period of time. Only a few studies have examined the relationship between maternal zinc and infant growth $(20,21)$. Our findings indicate that maternal vitamin $\mathrm{A}$ and $\mathrm{C}$ levels during pregnancy influence infant growth significantly, with vitamin A being continuously related to head circumference and vitamin $\mathrm{C}$ to head circumference and weight by the age of 3 years. Vitamin A has been implicated in the synaptic plasticity of the hippocampus and in cognitive functions, playing a major role in the development of the central nervous system (22). This could explain the association we observed between maternal vitamin A levels and infant head circumference. In addition, vitamin $\mathrm{C}$ protects the fetus from oxidative stress and is required for collagen synthesis, providing the basis for our findings of its association with weight (23).

Along with maternal vitamin status, we investigated maternal oxidative stress that might be activated under normal pregnancy circumstances and cause adverse outcomes such as low birth weight or preterm birth (24). Various free radicals are produced as a consequence of normal cellular metabolism, but if excessive free radicals are generated or are not removed properly by antioxidant defenses, oxidative stress may increase (25). Oxidative stress has been shown to be closely associated with antioxidant vitamin levels during pregnancy (26-29). Previous studies have demonstrated that low levels of the antioxidant vitamins $\mathrm{C}$ and $\mathrm{E}$ during pregnancy increase the level of maternal oxidative stress and influence the birth weight (23). It is presumed that this maternal oxidative stress might also be related to successive postnatal long-term growth, yet there has been no effort to follow up and observe these associations. Therefore, we measured the levels of oxidative stress, MDA, and 8-OHdG in the urine of mothers during pregnancy and examined their associations with infant growth over 3 years. Infants born to mothers with a high level of oxidative stress were shorter and weighed less for 3 years than did those born to mothers with a low level of oxidative stress. However, this effect disappeared after adjusting for other factors. Our findings are not in agreement with previous reports that oxidative stress causes increased vasoconstriction and reduces uteroplacental blood flow, impeding cell membranes and DNA (24). 
Table 5. Association between maternal antioxidant vitamin and oxidative stress levels and infant growth percentile adjusted for covariances

\begin{tabular}{|c|c|c|c|c|c|c|c|c|c|c|}
\hline \multirow[b]{2}{*}{ Infant growth } & \multicolumn{2}{|c|}{ Vitamin A } & \multicolumn{2}{|c|}{ Vitamin C } & \multicolumn{2}{|c|}{ Vitamin E } & \multicolumn{2}{|c|}{ MDA } & \multicolumn{2}{|c|}{$8-O H d G^{a}$} \\
\hline & Low & High & Low & High & Low & High & Low & High & Low & High \\
\hline \multicolumn{11}{|l|}{ Weight } \\
\hline At birth & 39.81 & 45.87 & 45.51 & 44.61 & 45.52 & 41.73 & 47.66 & 44.06 & 48.77 & 40.21 \\
\hline 6 months & 55.86 & 66.02 & 61.93 & 71.67 & 63.16 & 65.66 & 63.01 & 56.55 & 61.55 & 63.18 \\
\hline 12 months & 53.87 & 62.27 & 57.96 & 68.89 & $58.4 \mathrm{I}$ & 66.56 & 55.70 & 60.49 & 58.02 & 48.46 \\
\hline 18 months & 53.62 & 55.34 & 52.71 & 61.69 & 56.30 & 51.94 & 62.06 & 37.11 & 53.62 & - \\
\hline 24 months & 45.22 & 58.89 & 55.49 & 62.05 & 56.24 & 57.56 & 56.27 & 49.32 & 55.14 & 48.95 \\
\hline 36 months & 65.01 & 71.26 & 62.75 & 85.27 & 76.55 & 40.12 & 75.16 & 71.40 & 79.94 & 45.91 \\
\hline$P$ & \multicolumn{2}{|c|}{0.06} & \multicolumn{2}{|c|}{0.01} & \multicolumn{2}{|c|}{0.18} & \multicolumn{2}{|c|}{0.33} & \multicolumn{2}{|c|}{0.20} \\
\hline \multicolumn{11}{|l|}{ Height } \\
\hline At birth & 49.59 & 52.20 & 51.80 & 52.56 & 51.16 & 52.12 & 52.36 & 49.90 & 53.89 & 43.56 \\
\hline 6 months & 60.71 & 61.52 & 61.29 & 62.54 & 62.59 & 57.20 & 59.17 & 64.45 & 61.65 & 62.66 \\
\hline 12 months & 60.18 & 60.26 & 58.88 & 64.33 & 59.39 & 62.71 & 54.07 & 58.32 & 57.19 & 43.07 \\
\hline 18 months & 62.58 & 55.63 & 56.52 & 57.87 & 60.53 & 47.54 & 63.12 & 47.10 & 60.44 & - \\
\hline 24 months & 54.37 & 63.34 & 64.58 & 54.62 & 62.22 & 61.83 & 61.28 & 63.97 & 61.85 & 56.57 \\
\hline 36 months & 99.07 & 89.49 & 87.06 & 110.50 & 95.91 & 80.93 & 103.35 & 75.01 & 96.63 & 96.74 \\
\hline$p$ & \multicolumn{2}{|c|}{0.86} & \multicolumn{2}{|c|}{0.32} & \multicolumn{2}{|c|}{0.20} & \multicolumn{2}{|c|}{0.35} & 0.45 & \\
\hline \multicolumn{11}{|c|}{ Head circumference } \\
\hline At birth & 53.82 & 55.94 & 56.94 & 52.24 & 56.22 & 53.56 & 58.04 & 55.20 & 57.03 & 64.11 \\
\hline 6 months & 42.92 & 70.27 & 65.43 & 71.53 & 68.65 & 65.42 & 75.38 & 55.67 & 68.63 & 90.10 \\
\hline 12 months & 62.22 & 68.07 & 65.44 & 72.44 & 67.47 & 66.42 & 70.00 & 50.46 & 68.23 & 69.67 \\
\hline 18 months & 57.75 & 63.82 & 63.06 & 64.24 & 62.14 & 64.18 & 54.12 & 51.79 & 54.84 & - \\
\hline 24 months & 38.67 & 64.64 & 61.41 & 65.70 & 64.47 & 56.91 & 60.05 & 65.73 & 59.54 & 92.71 \\
\hline 36 months & 47.71 & 81.45 & 68.13 & 79.76 & 66.71 & 84.34 & 62.36 & 77.73 & 66.18 & 73.17 \\
\hline$p$ & \multicolumn{2}{|c|}{$<0.01$} & \multicolumn{2}{|c|}{0.34} & \multicolumn{2}{|c|}{0.86} & \multicolumn{2}{|c|}{0.60} & \multicolumn{2}{|c|}{0.15} \\
\hline
\end{tabular}

Adjusted for infant sex, gestational age, breastfeeding, period of breastfeeding, household income, and dietary supplementation.

${ }^{a}$ Not estimated using least-squares means because of a missing value at 18 months.

Our findings may have been underestimated by other unknown factors and may not indicate causality. Thus, further studies are needed to clarify the effect of oxidative stress and how it affects a child's growth.

Because the categorization of the subjects into groups with high and low levels of vitamins and stress was not randomly allocated, those two groups might have had different characteristics. These characteristics may be closely correlated with both maternal vitamin and oxidative stress levels and infant growth, intervening with and confounding the inherent relationship. Hence, various factors affecting the level of maternal vitamins and oxidative stress, such as biological, environmental, or socioeconomic factors, should be considered (30). At the same time, factors influencing infant growth (e.g. genetic factors, a sufficient nutritional supply from the mother, the ability of the placenta to deliver nutrients, and intrauterine hormone levels) as well as environmental conditions, the maternal physical status, parity, maternal nutrition level, and fetal gender should be considered (31). Moreover, infant growth after birth might be significantly affected by such factors. Consequently, we selected potential confounding variables with possible effects on infant growth and found that antioxidative vitamin levels were more closely related to infant growth than was oxidative stress. The effect of oxidative stress might have been underestimated by measurement error.

There are several limitations in this study. First, because there are no definite criteria for the vitamin and oxidative stress levels for pregnant women (32), percentiles were used to categorize the subjects into groups with high and low levels of vitamins and stress. Second, maternal vitamin and oxidative stress levels were measured only once at mid-term pregnancy and thus did not reflect the general maternal levels throughout pregnancy (33). We took measurements at 24-28 weeks of pregnancy because this period is known to be associated with the highest levels of lipid peroxidation. Third, only infants followed up for 3 years were included; thus, there is a possibility that infants with specific characteristics may have been excluded in a biased manner. Followed-up mothers were more likely to have a high maternal level of vitamin A and 

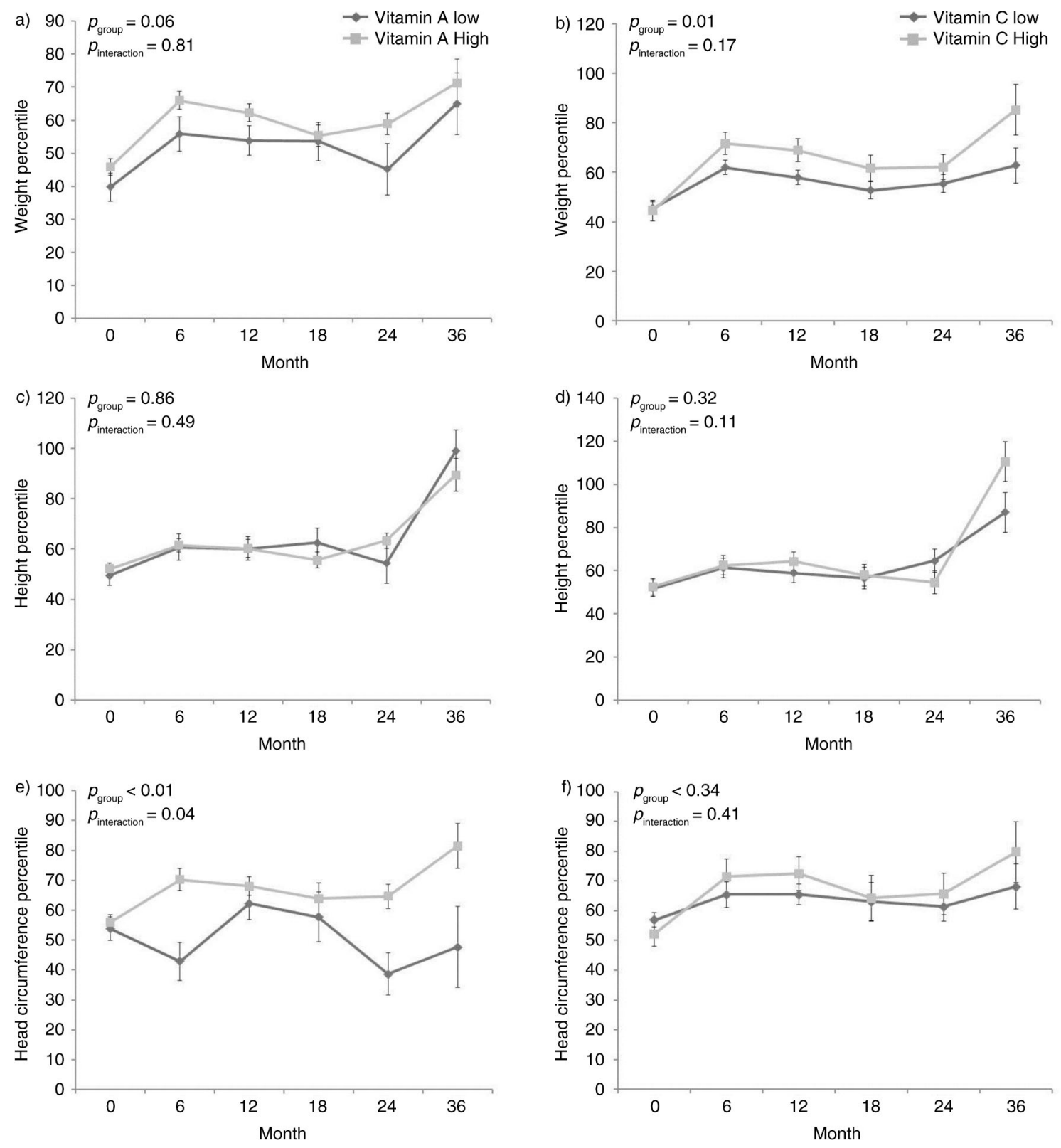

Fig. 2. Association between maternal vitamins $\mathrm{A}$ and $\mathrm{C}$ and infant growth.

The least-squares mean value of infant growth adjusted for infant sex, gestational age, breastfeeding, period of breastfeeding, household income, and dietary supplementation during the first 3 years of life according to antioxidative vitamin A (panels a, c, e) and vitamin $\mathrm{C}$ (panels b, d, f) levels. Bar heights represent 95\% confidence intervals.

to care for their infants themselves. Finally, residual confounding factors such as lifestyle behaviors could have affected the results, but this limitation does not threaten the main findings because we considered many relevant potential confounding factors.

In conclusion, intervention supporting an antioxidant diet and supplementation with appropriate levels of vitamins $\mathrm{A}$ and $\mathrm{C}$ are needed during pregnancy. Because fetal growth factors can be determined before pregnancy, such as at conception or throughout maternal life (30), measuring and augmenting maternal nutrition before pregnancy could be a more effective strategy for improving infant growth (32).

\section{Acknowledgements}

This work was supported by a National Research Foundation of Korea Grant funded by the Korean government (2009-0064004).

\section{Conflict of interest and funding}

The authors have not received any funding or benefits from industry or elsewhere to conduct this study. 


\section{References}

1. Barker DJP. The developmental origins of adult disease. Eur J Epidemiol 2003; 18: 733-6.

2. Dewey KG. Cross-cultural patterns of growth and nutritional status of breast-fed infants. Am J Clin Nutr 1998; 67: 10-7.

3. Bhandari N, Bahl R, Taneja S. Effect of micronutrient supplementation on linear growth of children. Br J Nutr 2001; 85(Suppl 2): S131-7.

4. Franco Mdo C, Dantas APV, Akamine EH, Kawamoto EM, Fortes ZB, Scavone C, et al. Enhanced oxidative stress as a potential mechanism underlying the programming of hypertension in utero. J Cardiovasc Pharmacol 2002; 40: 501-9.

5. Dejmek J, Ginter E, Solansky I, Podrazilova K, Stavkova Z, Benes I, et al. Vitamin C, E and A levels in maternal and fetal blood for Czech and Gypsy ethnic groups in the Czech Republic. Int J Vitam Nutr Res 2002; 72: 183-90.

6. Hininger I, Favier M, Arnaud J, Faure H, Thoulon JM, Hariveau E, et al. Effects of a combined micronutrient supplementation on maternal biological status and newborn anthropometrics measurements: a randomized double-blind, placebo-controlled trial in apparently healthy pregnant women. Eur J Clin Nutr 2004; 58: 52-9.

7. Luo ZC, Fraser WD, Julien P, Deal CL, Audibert F, Smith GN, et al. Tracing the origins of "fetal origins" of adult diseases: programming by oxidative stress? Med Hypotheses 2006; 66: $38-44$.

8. Bland JM, Altman D. Statistical methods for assessing agreement between two methods of clinical measurement. Lancet 1986; 1: 307-10.

9. Korean Pediatric Society (2007). Korean infants and adolescents growth standards. Seoul: The Korean Pediatric Society.

10. Cole TJ. The LMS method for constructing normalized growth standards. Eur J Clin Nutr 1990; 44: 45-60.

11. WHO Multicenter Growth Reference Study Group (2006). WHO Child Growth Standards: length/height-for-age, weightfor-age, weight-for-length, weight-for-height and body mass index-for-age: methods and development. Geneva: World Health Organization.

12. Leary S, Ness A, Emmett P, Smith GD. Maternal diet in pregnancy and offspring height, sitting height, and leg length. J Epidemiol Community Health 2005; 59: 467-72.

13. Doyle W, Crawford MA, Wynn MA, Wynn SW. The association between diet and birth dimensions. J Nutr 1990; 1: 9-17.

14. Burke B, Harding J, Stuart H. Nutrition studies during pregnancy IV, relation of protein content of mother's diet during pregnancy to birth length, birth weight, and condition of infant at birth. J Pediatr 1948; 32: 506-15.

15. Stein Z, Susser M, Marolla F. Famine and human development: the Dutch hunger winter of 1944/45. New York: Oxford University Press; 1975.

16. Godfrey KM, Barker DJ, Robinson S, Osmond C. Maternal birthweight and diet in pregnancy in relation to the infant's thinness at birth. Br J Obstet Gynaecol 1997; 104: 663-7.

17. Rijken M, Wit JM, Cessie SL, Veen S. The effect of perinatal risk factors on growth in very preterm infants at 2 years of age: The Leiden Follow-up Project on Prematurity. Early Hum Dev 2007; 83: 527-34.

18. Forslund M, Bjerre I. Follow-up of preterm children: II. Growth and development at four years of age. Early Hum Dev 1990; 24: 107-18.

19. Cole TJ, Bellizzi MC, Flegal KM, Dietz WH. Establishing a standard definition for child overweight and obesity worldwide: international survey. BMJ 2000; 320: 1-6.
20. Osendarp SJ, van Raaij JM, Darmstadt GL, Baqui AH, Hautvast JG, Fuchs GJ. Zinc supplementation during pregnancy and effects on growth and morbidity in low birthweight infants: a randomised placebo controlled trial. Lancet 2001; 357: $1080-5$.

21. Iannotti LL, Zavaleta N, León Z, Shankar AH, Caulfield LE. Maternal zinc supplementation and growth in Peruvian infants. Am J Clin Nutr 2008; 88: 154-60.

22. Kheirvari S, Uezu K, Sakai T, Nakamori M, Alizadeh M, Sarukura $\mathrm{N}$, et al. Increased nerve growth factor by zinc supplementation with concurrent vitamin A deficiency does not improve memory performance in mice. J Nutr Sci Vitaminol 2006; 52: 421-7.

23. Lee BE, Hong YC, Lee KH, Kim YJ, Kim WK, Chang NS, et al. Influence of maternal serum levels of vitamins $\mathrm{C}$ and $\mathrm{E}$ during the second trimester on birth weight and length. Eur $\mathrm{J}$ Clin Nutr 2004; 58: 1365-71.

24. Park BY, Kim YJ, Park EA, Lee HY, Ha EH, Park JS, et al. Myeloperoxidase polymorphism and vitamin $\mathrm{C}$ levels during pregnancy affect maternal oxidative stress and their neonatal birth weights. J Toxicol Pub Health 2004; 3: 187-93.

25. Sugino N, Takiguchi S, Umekawa T, Heazell A, Caniggia I. Oxidative stress and pregnancy outcome: a workshop report. Placenta 2007; 28(Suppl A): S48-50.

26. Park HS, Kim YU, Ha EH, Lee HY, Chang NS, Hong YC, et al. The risk of MTHFR variants, folate and vitamin $\mathrm{B}_{12}$ deficiencies and hyperhomocysteinaemia during pregnancy associated with short gestational age and reduced birth weight. Environ Mutagen Carcinog 2003; 23: 1-6.

27. Kang SS, Wong PW, Norusis M. Homocysteinemia due to folate deficiency. Metabolism 1987; 36: 458-62.

28. Stabler SP, Marcell PD, Podell ER, Allen RH, Savage DG, Lindenbaum J. Elevation of total homocysteine in the serum of patients with cobalamin or folate deficiency detected by capillary gas chromatography-mass spectrometry. J Clin Invest 1988; 81: 466-74.

29. Ubbink JB, van der Merwe A, Vermaak WJ, Delport R. Hyperhomocysteinemia and the response to vitamin supplementation. Clin Investig 1993; 71: 993-8.

30. Maternal nutrition and fetal growth and development. In: P Gluckman, M Hanson, eds. Developmental origins of health and disease, Chap. 8. New York: Cambridge University Press; 2006. pp. 98-129.

31. Pallotto EK, Kilbride HW. Perinatal outcome and later implications of intrauterine growth restriction. Clin Obstet Gynecol 2006; 49: 257-69.

32. Mora JO, Nestel PS. Improving prenatal nutrition in developing countries: strategies, prospects, and challenges. Am J Clin Nutr 2000; 71(Suppl 5): 1353S-63.

33. Uotila J, Tuimala R, Aarnio T, Pyykkö K, Ahotupa M. Lipid peroxidation products, selenium-dependent glutathione peroxidase and vitamin E in normal pregnancy. Eur J Obstet Gynecol Reprod Biol 1991; 42: 95-100.

\footnotetext{
*Hyesook Park

Department of Preventive Medicine

School of Medicine

Ewha Womans University

9|1-। Mok-6-dong

Yangcheon-Gu, Seoul I58-7I0

South Korea

Email: hpark@ewha.ac.kr
} 